\title{
Faktor-Faktor Yang Mempengaruhi Kesadaran Ekologis Siswa Pada Pembelajaran Berbasis Ekopedagogik di Sekolah Dasar
}

\author{
Budi Hendrawan¹, Mohammad Fahmi Nugraha', Fajar Nugraha² \\ 'Prodi PGSD Universitas Muhammadiyah Tasikmalaya, Jl. Tamansari Km. 2,5 Mulyasari, Tamansari \\ Kota Tasikmalaya, Jawa Barat \\ ${ }^{2}$ Prodi PGPAUD Universitas Muhammadiyah Tasikmalaya, Jl. Tamansari Km. 2,5 Mulyasari, Tamansari \\ Kota Tasikmalaya, Jawa Barat \\ Correspondence Email: hendrawan_budy@umtas.ac.id
}

\begin{abstract}
The purpose of this study was to determine the factors that could affect students' ecological awareness in learning ecopedagogy in elementary schools. The method used in this research is a descriptive method. The descriptive method is used to map the factors that can affect students' ecological awareness through ecopedagogy-based learning in elementary schools. The results obtained from the research that have been carried out are factors that can affect students' ecological awareness, including the elimination of PLH subjects in the 2013 curriculum, the lack of facilities and infrastructure that support the implementation of PLH learning in elementary schools, including greenland in schools, especially in urban schools, the lack of learning tools and media, lack of PLH learning resources both from the aspect of educators and learning resources in the form of textbooks on ecopedagogy, lack of strategies or methods in implementing eco pedagogical learning in elementary schools, no role models or examples in students' daily life in environmental preservation, and students do not care enough about the environment. So, it can be concluded that there are several factors that affect the ecological awareness of students in learning ecopedagogy, the main ones are the basic environmental policy for teaching and learning in the curriculum, learning facilities and infrastructure, students' attitudes towards environmental education learning and media, tools, and teaching methods. The impact that occurs, students' knowledge of the environment is very lacking, lack of awareness of the surrounding environment, and lack of motivation to preserve the environment around students.
\end{abstract}

Keywords:

Facto-factors; Ecological Awareness; Learning; Ecopedagogy; Primary school

\begin{abstract}
Abstrak
Tujuan penelitian ini adalah untuk mengetahui faktor-faktor yang dapat mempengaruhi kesadaran ekologis siswa pada pembelajaran ekopedagogik di sekolah dasar. Metode yang digunakan dalam penelitian ini adalah metode deskriptif. Metode deskriptif yang digunakan untuk memetakan factorfaktor yang dapat mempengaruhi kesadaran ekologis siswa melalui pembelajaran berbasis Ekopedagogik di Sekolah Dasar. Hasil yang diperoleh dari penelitian yang telah dilakukan factor-faktor dapat mempengaruhi kesadaran ekologis siswa diantaranya adalah dihapuskannya mata pelajaran PLH pada kurikulum 2013, kurangnya sarana dan prasarana yang mendukung dalam pelaksanaan pembelajaran PLH di Sekolah Dasar diantaranya lahan hijau di sekolah khususnya di sekolah perkotaan, kurangnya alat dan media pembelajaran, kurangnya sumber belajar PLH baik dari aspek pendidik maupun sumber belajar berupa buku pelajaran tentang ekopedagogik, kurang strategi atau metode dalam pelaksanaan pembelajaran ekopedagogik di Sekolah Dasar, tidak adanya role model atau contoh dalam kehidupan sehari-hari siswa dalam pelestarian lingkungan, dan kurang rasa peduli siswa terhadap lingkungan sekitar. Maka, dapat diperoleh kesimpulan bahwa ada beberapa factor yang mempengaruhi kesadaran ekologis siswa dalam pembelajaran ekopedagogi yang utama adalah Kebijakan landasar pembelajaran PLH di kurikulum, Sarana dan Prasarana pembelajaran, Sikap Siswa terhadap Pembelajaran PLH dan media, alat, Metode pembelajaran PLH. Dampak yang terjadi, pengetahuan siswa tentang lingkungan sangat kurang menguasai, kurangnya kesadaran terhadap lingkungan sekitar, dan kurangnya motivasi untuk menjaga kelestarian lingkungan sekitar siswa.
\end{abstract}

Kata Kunci:

Faktor-faktor; Kesadaran Ekologis; Pembelajaran; Ekopedagogik; Sekolah Dasar 
2 | Naturalistic: Jurnal Kajian Penelitian dan Pendidikan dan Pembelajaran, Volume 5 Issue 1, Oktober 2020 Hal 684-691 


\section{Pendahuluan}

Ekopedagogik ini menjadi bagian dari pedagogik (ilmu pendidikan) kritis sebagai bentuk kritis dan kepedulian terhadap keadaan sosial manusia, tanpa hubungan baik dengan alam manusia tidak mungkin bisa hidup dengan nyaman. Sudah sepantasnya ekopedagogik menjadi bagian dari edukasi dan pembelajaran bagi siswa di Sekolah-sekolah. Menurut Grigorov [1] Ekopedagogik berfungsi untuk menyadarkan siswa akan arti pentingnya lingkungan termasuk ke dalam pemikiran baru sebagai bentuk pandangan kritis terhadap sistem pendidikan yang ada.

Ekopedagogik merupakan tipe pembelajaran berbasis cinta, partisipasi, dan kreativitas (Surata, 2013) [2]. Kenyataan saat ini, sebagian siswa di Sekolah Dasar banyak belum memperlihatkan sikap peduli terhadap lingkungan sekitar, meskipun dalam keseharian mereka kadang selalu diberikan pengetahuan untuk selalu hidup bersih dan sehat, akan tetapi hal tersebut hanya sebagai formalitas sebagai bentuk tugas dari guru saja tanpa adanya tindak lanjut dan menjadikan kesadaran bagi siswa sendiri. Menurut Yunansah [3] upaya untuk menjaga keselarasan, keharmonisan dan kesinambungan alam sungguh berbanding terbalik dengan realitas yang ada saat ini. Meskipun pada dasarnya alam sendiri sudah diakui memiliki nilai dan berharga, tetapi pada kenyataannya, alam dianggap sebagai objek kehidupan yang terus dieksploitasi oleh manusia melalui praktik pencemaran, perusakan dan berbagai tindakan buruk lainnya.

Observasi yang dilakukan ke sekolah-sekolah di masih banyak ditemukan sistem pembelajaran yang dilaksanakan dengan output yang dihasilkan, masih banyak siswa hanya menjadi generasi penghafal bukan generasi kritis dan literat dengan pengetahuan yang telah mereka pelajari, kebanyakan saat ini siswa sudah tidak peduli dengan keadaan lingkungan alam sekitar, yang ditakutkan menjadikan mereka kelak penganut pragmatismaterialis. Karena, proses pembelajaran yang memuat materi ekopedagogik hanya terdapat dalam beberapa mata pelajaran saja diataranya Ilmu Pengetahuan Alam dan Pendidikan Lingkungan Hidup (PLH), dalam kurikulum 2013 yang berlaku di Sekolah Dasar saat ini PLH bukan menjadi mata pelajaran wajib yang harus dipenuhi oleh siswa, hal ini justru semakin membuat pesimis bagi guru dalam menumbuhkan kesadaran ekologis siswa, yang seharunya terintegrasi dalam setiap mata pelajaran yang diberikan.

Efek kemajuan teknologi bisa saja memberikan pengaruh signifikan terhadap kehidupan siswa sekolah dasar, akan tetapi jika pemangku kepentingan di Sekolah memiliki tanggung jawab dan kritis terhadap teknologi maka keseimbangan antara pengetahuan, sikap, dan keterampilan siswa untuk selalu peduli dan menjaga lingkungan alam sekitar. Berdasarkan uraian tersebut, peneliti akan mengkaji tentang kesadaran ekologis siswa dalam Pembelajaran di Sekolah Dasar berbasis Ekopedagogik dengan tujuan untuk melihat dan memetakan kesadaran ekologis siswa dalam pembelajaran berbasis Ekopedagogik pada mata pelajaran IPA dan PLH di Sekolah Dasar.

Berdasarkan latar belakang di atas, tujuan penelitian ini sebagai berikut Mengidentifikasi faktor-faktor yang mempengaruhi kesadaran ekologis siswa pada pembelajaran berbasis Ekopedagogik. Penelitian ini 
menggunakan metode deskriptif. Metode deskriptif digunakan untuk memetakan faktor-faktor yang mempengaruhi kesadaran ekologis siswa melalui pembelajaran berbasis Ekopedagogik di Sekolah Dasar. Populasi dalam penelitian ini seluruh Sekolah Dasar di Kota Tasikmalaya, sedangkan penentuan sampel penelitian dengan menggunakan teknik random sampling dari SD di Kota Tasikmalaya mulai dari kelas 1 s/d kelas 6 sebanyak 60 siswa dan guru sekolah dasar sebanyak 27 orang guru.

\section{Hasil dan Pembahasan}

1. Hasil Deskripsi faktor-faktor yang mempengaruhi kesadaran ekologis siswa pada pembelajaran berbasis Ekopedagogik

Dalam penelitian ini yang menjadi tujuan kedua selain tingkat kesadaran ekologis siswa yaitu mengetahui faktor-faktor yang mempengaruhi kesadaran ekologis siswa pada pembelajaran Ekopedagogik di sekolah Dasar. Pembelajaran ekopedagogik di sekolah dasar masuk dalam mata pelajaran Pendidikan Lingkungan Hidup dan Ilmu Pengetahuan Alam. Untuk memperoleh data tentang hal tersebut peneliti menggunakan instrument wawancara secara terstuktur kepada guru sekolah dasar yang pernah melakukan pembelajaran ekopedagogik, serta untuk mengetahui berbagai informasi seputar pelaksanaan pembelajaran Ekopedagogik.

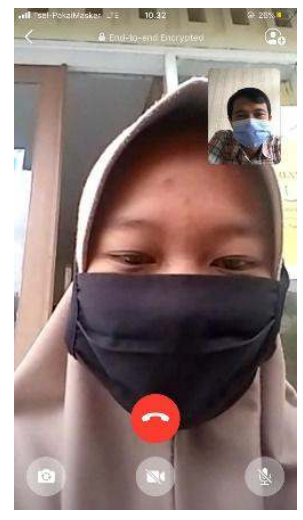

Gambar 1. Wawancara online dengan Guru SD Attaufiq Al-Islamy Kota Tasikmalaya

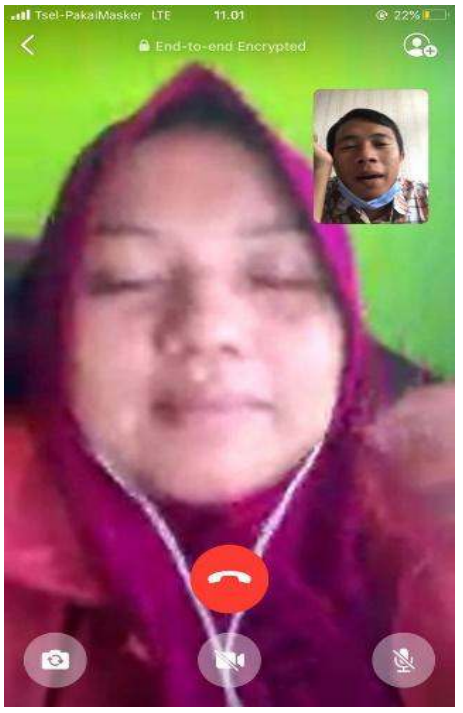

Gambar 2. Wawancara online dengan Guru SDN Tugu Kota Tasikmalaya

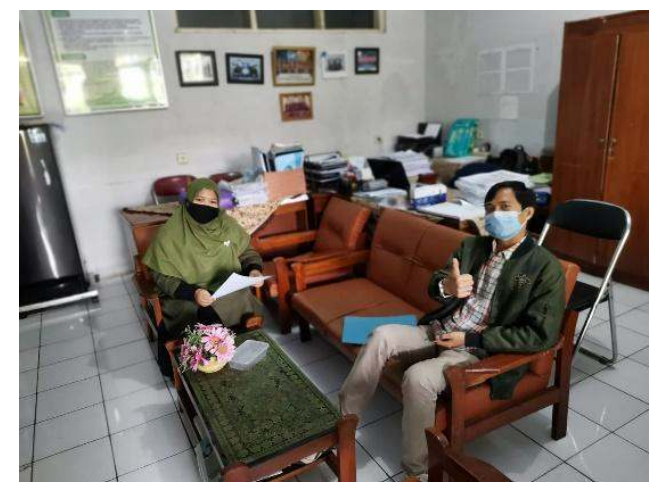

Gambar 3. Wawancara langsung dengan Guru SDN 1 Nagarawangi Kota Tasikmalaya 


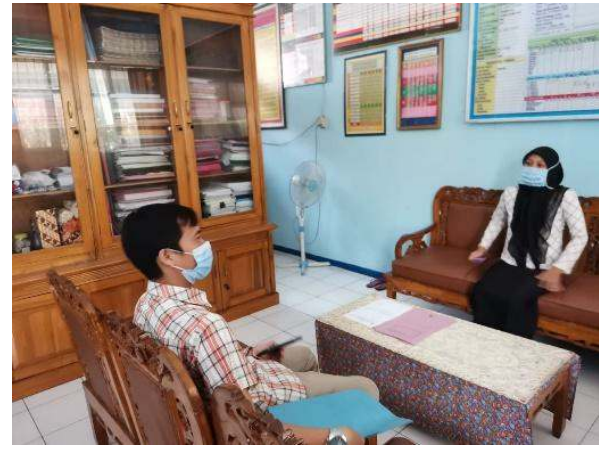

Gambar 4. Wawancara langsung dengan Guru SDN 2 Sukamanah

Hasil yang diperoleh dari wawancara dengan guru sekolah dasar di Kota Tasikmalaya yang diambil sebanyak 26 guru secara random, dengan mengajukan 9 pertanyaan secara terstruktur:

\subsection{Deskripsi wawancara dengan guru tentang PLH}

Diperoleh gambaran umum guru di Kota Tasikmalaya tentang PLH baik dalam aspek pengetahuan maupun keterampilannya bahwa secara umum guru menjawab "Pendidikan Lingkungan Hidup”, karena sebagaimana yang tertuang dalam kurikulum di Sekolah Dasar yang telah digunakan bahwa PLH itu merupakan salah satu mata pelajaran yang harus dipelajari di Sekolah Dasar, namun demikian ada yang hanya memberikan jawaban Tahu, kemudian ada juga yang menjawab bahwa PLH “ Pendidikan tentang keadaan di Lingkungan sekitar". Maka dapat digambarkan secara umum hampir $100 \%$ responden memberikan jawaban bahwa PLH itu merupakan pendidikan Lingkungan Hidup. Hal tersebut diperjelas oleh Fien et al. [4] PLH juga merupakan dasar-dasar pendidikan dalam proses pemecahan masalah lingkungan hidup dengan dasar filosofis keseluruhan, kelestarian, peningkatan dan pemeliharaan agar semuanya menjadi lebih baik.

\subsection{Deskripsi wawancara tentang seberapa penting PLH diberikan kepada Siswa}

Diperoleh gambaran hasil wawancara yang dilakukan kepada guru rata-rata menjawab sangat penting, penting. Ini menunjukkan bahwa kesadaran tentang pentingnya mata pelajaran ini sudah menjadi kebutuhan bagi guru dalam upaya memberikan Pendidikan lingkungan hidup. Karena sejatinya sesuai yang diungkapkan Khan [5] menjelaskan ekopedagogik merupakan sebagai gerakan akademik untuk menyadarkan para peserta didik menjadi seorang individu yang memiliki, pemahaman, kesadaran, dan keterampilan hidup selaras dengan kepentingan pelestarian alam. Oleh karena itu, sudah kewajiban guru untuk terus memberikan pengetahuan, keterampilan, sikap kepada siswa agar senantiasa menjaga kelestarian lingkungan.

\subsection{Deskripsi wawancara tentang seberapa penting Pelaksanaan Pembelajaran Ekopedagogik (PLH) di Sekolah Dasar}

Hasil wawancara ini akan memberikan gambaran umum tentang pelaksanaan pembelajaran ekopedagogik yang dilaksanakan di sekolah dasar melalui pembelajaran PLH. Data yang diperoleh dari responden secara umum menjawab bahwa pelaksanaan pembelajaran ekopedagogik di Sekolah Dasar rata-rata sudah tidak ada dalam mata pelajaran di SD karena sejak kurikulum 2013 digunakan di sekolahsekolah mata pelajaran ekopedagogik atau Pendidikan Lingkungan Hidup dihapuskan, "Dalam kurikulum 2013 sudah tidak ada. Tapi untuk penerapannya dilaksanakan dalam pembiasaan", sementara itu ada yang mengungkapkan pembelajaran ekopedagogik dengan cara menjaga 
lingkungan, melaksanakan piket kelas, juga menjelaskan pembelajaran ekopedagogik dilaksanakan terintegrasi dengan muatan pembelajaran tematik. Maka, bisa dikatakan juga pembelajaran ekopedagogik dalam mata pelajaran PLH di sekolah Dasar hampir Sebagian besar sudah tidak dilaksanakan akan tetapi masih ada terintegrasi dalam muatan pembelajaran tematik di kurikulum 2013 meskipun tidak komprehensif. Namun demikian, harus ada penegasan Kembali tentang Pendidikan lingkungan hidup agar dijadikan pedoman serta ramburambu bagi guru dalam memberikan Pendidikan dengan lingkungan kepada siswa khususnya di sekolah dasar. Hal ini sejalan dengan yang disampaikan oleh Tara [6] bahwa salah satu aspek utama dalam memajukan pendidikan berwawasan lingkungan adalah dengan mengembangkan kurikulum lingkungan hidup yang telah ada saat ini.

\subsection{Deskripsi wawancara tentang strategi atau metode dalam melaksanakan pembelajaran PLH dalam pembelajaran}

Responden menjawab dengan beragam tapi dari Sebagian besar narasumber yang diwawancarai diperoleh hasil bahwa strategi atau metode yang digunakan dalam melaksanakan pembelajaran ekopedagogik (PLH) di Sekolah Dasar menggunakan metode yang dipakai dalam pembelajaran tematik seperti biasa dan melibatkan siswa secara langsung dalam pembelajaran melalui strategi yang menarik, selanjutnya memberikan penjelasan pembelajaran ekopedagogik dilaksanakan melalui pembiasaan. Kegiatan tersebut bisa berupa langsung praktek di lingkungan sekitar sekolah seperti buang sampah pada tempatnya, membiasakan merawat tanaman yang ada di sekitar lingkungan sekolah. dan melatih kreativitas siswa seperti membuat hiasan kelas dari barangbarang bekas yang sudah tidak terpakai lagi. Metode pembiasaan bisa menjadi suatu metode yang baik untuk dipakai dalam pembelajaran ekopedagogik sebagaimana menurut P. Joko Subagyo dalam Arif [7] menyatakan bahwa kondisi senyatanya dari masyarakat kita mengenai kesadaran lingkungan hidup ini nampaknya masih tercermin salah satunya tentang tanggungjawab mengenai kelestarian alam masih perlu diperbaiki dan ditingkatkan kembali.

\subsection{Deskripsi wawancara tentang kendala atau hambatan dalam melaksanakan pembelajaran PLH di sekolah dasar}

Gambaran umum dari hasil wawancara tentang hambatan yang ditemukan dalam pelaksanaan pembelajaran ekopedagogik (PLH) di sekolah dasar adalah tidak adanya mata pelajaran PLH dalam kurikulum 2013, sehingga menjadi suatu kendala yang berarti bagi guru dan tidak ada pedoman yang ajeg untuk dijadikan rujukan dan dasar bagi Pendidikan lingkungan hidup secara luas kepada siswa sekolah dasar, selain itu kendala atau hambatannya yakni sarana dan prasarana, berupa lahan dan alat pembelajaran khusus dalam Pendidikan lingkungan, buku sumber pelajaran yang sangat jarang, bahkan kurangnya lahan hijau di sekitar sekolah. Sehingga menjadi kendala sebagai sumber belajar langsung bagi siswa. Media pembelajaran dan pendaanan dalam pengadaan green house juga menjadi satu kendala yang diungkapkan oleh guru, juga waktu dan jam pelajaran yang sangat terbatas sehingga penguasaan siswa kurang begitu luas dan mendalam. Sehingga harus lebih kepada upaya pengembangan bahan ajar yang memadai, media pembelajaran yang beragam dan didukung oleh tenaga pendidika yang 
sesuai dengan bidang Pendidikan lingkungan hidup. Karena kesadara lingkungan sangat diperlukan bagi siswa untuk selalu memiliki kesadaran dan kecerdasarn ekologis agar memiliki rasa kepedulian untuk senantiasa menjaga lingkungan. Sebagaimana menurut Herlambang [8] bahwa kesadaran ekologis harus menjadi bagian terpenting dari tujuan Pendidikan.

\subsection{Deskripsi wawancara tentang solusi yang dapat lakukan dalam menanggulangi berbagai kendala atau hambatan dalam pembelajaran PLH}

Hasil yang diperoleh dari wawancara tentang solusi yang dapat dilakukan diperoleh gambaran umum bahwa guru harus kreatif dalam mencari sumber referensi seperti dari internet atau berupa video pembelajaran edukasi tentang lingkungan. Selain itu, memanfaatkan sumber dan media yang ada dilingkungan itu menjadi salah satu solusi yang bisa digunakan guru dalam upaya menanggulangi kendala atau hambatan dalam pembelajaran PLH di Sekolah Dasar seperti bantuan orang tua untuk bersinergi agar siswa memiliki kebiasaan yang baik dalam menjaga lingkungan, membuat tanaman hidroponik di depan kelas, menanam menggunakan tabulampot di lingkungan sekolah, selain itu dengan tetap konsisten dengan kesepakatan serta tetap memberikan contoh yang baik sehingga siswa menemukan role model yang tepat dan melengkapi sarana penunjang dalam pembelajaran PLH atau ekopedagogik di sekolah dasar. Karena salah satu prinsip Prinsip implementasi pendidikan berbasis Ekopedagogik adalah Pembelajaran berbasis ekopedagogik menekankan pada pengembangan materi yang tidak hanya terbatas pada sesuatu yang bersifat tekstual, melainkan perlu dikembangkan melalui pendekatan kontekstual, artinya bahwa pembelajaran secara esensial harus dikembangkan dengan menggunakan sumber dan media yang berada dalam konteks kehidupan peserta didik, agar peserta didik mampu mengkonstruksi pengetahuan secara bermakna. (Herlambang, 2018).[8]

\subsection{Deskripsi wawancara tentang respon siswa selama mengikuti pembelajaran PLH}

Gambaran umum yang diperoleh berdasarkan hasil wawancara dengan guru sekolah dasar di Kota Tasikmalaya bahwa siswa dalam mengikuti pembelajaran PLH atau ekopedagogik memiliki respon baik dan sangat antusias. Terutama jika materi yang diberikan berkaitan dengan kehidupan sehari-hari, melalui kegiatan praktikum, metode yang digunakan melalui pengalaman langsung oleh siswa sehingga selalu antusias. Sehingga hal ini, diharapkan siswa tidak mengalamai kejenuhan selama proses pembelajaran berlangsung. Sebagaimana menurut herlambang [8] bahwa prinsip pembelajaran berbasis ekopedagogik tidaklah dikembangkan berdasarkan pada orientasi pencapaian domain kognitif semata, melainkan harus mencakup multidomain yang meliputi kognitif, afektif, dan psikomotorik.

\subsection{Deskripsi wawancara tentang hal yang dilakukan untuk membangkitkan semangat siswa dalam pembelajaran PLH}

Guru sebagai narasumber dalam wawancara yang dilakukan mengungkapkan bahwa dalam membangkitkan semangat siswa dalam pembelajaran PLH di sekolah dasar salah satunya dengan pembelajaran outdoor, praktek langsung di lingkungan sekitar, seperti menyiram tanaman di lingkungan sekolah secara rutin dan merawatnya, melakukan perlombaan membuat 
prakarya dengan tema lingkungan secara individu dan kelompok, dengan penugasan membawa alat praktikum dari rumah sehingga siswa diberikan penghargaan bagi siswa yang berprestasi dalam bidang lingkungan. Selain itu, melalui motivasi yang diberikan oleh guru, menanamkan rasa cinta terhadap lingkungan. Karena kalau anak anak sudah mempunyai sifat sadar akan lingkungan maka pembelajaran Lingkungan hidup akan lebih mudah di kembangkan, dan membuat metode pembelajaran dalam kelas yang menarik seperti dengan tepukan atau nyanyian agar mudah mengingat. Karena salah satu tujuan ekopedagogik menurut Gyallay dalam Muhaimin [9] Untuk menciptakan pola perilaku yang baru pada individu, kelompok, dan masyarakat sebagai suatu keseluruhan terhadap lingkungan. Tujuan yang ingin dicapai tersebut meliputi aspek (a) kognitif; (b) sikap; (c) kepedulian; (d) keterampilan; dan (e) partisipasi.

\subsection{Deskripsi wawancara upaya yang} dilakukan untuk meningkatkan kesadaran lingkungan bagi siswa

Diperoleh gambaran umum bawah ada berbagai upaya yang dilakukan oleh guru dalam meningkatkan kesadaran ekologis bagi siswa khususnya di sekolah dasar, salah satu diantaranya yaitu dengan pembiasaan, memberikan nasihat dan contoh supaya siswa mengikuti setiap kegiatan yang positif untuk selalu menjaga lingkungan dan memiliki kesadaran lingkungan, terus memberikan pengertian dan memberikan contoh dampak positif dan negatif dari menjaga kelestarian lingkungan, seperti mewajibkan agar anak selalu membuang sampah pada tempatnya, membantu anak supaya membersihkan kelas, sebelum belajar siswa menyiram serta merawat tanaman yang telah mereka sendiri supaya tanaman tersebut tetap subur, sebelum pembelajaran daring dilakukan di kelas yaitu membuat ecobrick dengan cara membawa sampah plastik kering dimasukan ke botol air minum plastik sehingga membentuk kebiasaan sadar lingkungan tanpa diperintah siswa akan memasukan sampah plastik ke dalam botol dengan sendirinya, menayangkan video dampak positif dan negatif tentang menjaga dan merusak lingkungan sekitar, pengenalan akan dampak kerusakan alam serta mengajak anak melakukan hal-hal sederhana dimulai dari diri sendiri untuk menjaga lingkungan, sehingga dapat menanamkan rasa cinta pada lingkungan sedari dini. Karena menurut Gidley [1] Ecopedagogy bertujuan untuk memberikan anak- anak dan siswa dari segala usia pengetahuan tentang cara mengatasi masalah kontemporer dan masa depan yang paling serius, di antaranya adalah perusakan Alam - udara, air, makanan, hutan, hewan dan tumbuhan; perubahan iklim; fracking (rekahan hidrolik) dan geoengineering; penipisan lapisan ozon; kerusakan kota; krisis komunikasi manusia; ketergantungan teknologi; perlindungan anak-anak yang menggunakan Internet; perang tanpa akhir; dan banyak lainnya

\section{Simpulan}

Berdasarkan hasil penelitian yang telah dilakukan tentang faktor-faktor dapat mempengaruhi kesadaran ekologis siswa diantaranya adalah dihapuskannya mata pelajaran PLH pada kurikulum 2013, kurangnya sarana dan prasarana yang mendukung dalam pelaksanaan pembelajaran PLH di Sekolah Dasar diataranya lahan hijau di sekolah khususnya di sekolah perkotaan, kurangnya alat dan media pembelajaran, kurangnya sumber belajar PLH baik dari aspek pendidik maupun sumber belajar berupa buku pelajaran tentang ekopedagogik, kurang strategi atau 
metode dalam pelaksanaan pembelajaran ekopedagogik di Sekolah Dasar, tidak adanya role model atau contoh dalam kehidupan sehari-hari siswa dalam pelestarian lingkungan, dan kurang rasa peduli siswa terhadap lingkungan sekitar. Maka, dapat diperoleh kesimpulan bahwa ada beberapa factor yang mempengaruhi kesadaran ekologis siswa dalam pembelajaran ekopedagogi yang utama adalah Kebijakan landasar pembelajaran PLH di kurikulum, Sarana dan Prasarana pembelajaran, Sikap Siswa terhadap Pembelajaran PLH.

\section{Daftar Pustaka}

Grigorov, S.K and Fleuri, R.M. (2012). Ecopedagogy: Educating for New eco-social intercultural perspective. Visão Global, Joaçaba, v. 15, n. 1-2, p. 433-454, jan./dez. 2012.

Surata, S.P.K. (2013). Pembelajaran Lintas Budaya: Penggunaan Subak sebagai Model "Ecopedagogy. Jurnal Kajian Bali. Vol. 3 No.2, 181-198.

Yunansah, H \& Y.T Herlambang. (2017). Pendidikan Berbasis Ekopedagogik dalam Menumbuhkan Kesadaran Ekologis dan Mengembangkan Karakter Siswa Sekolah Dasar (Sebuah Telaah Kritis Dalam Perspektif Pedagogik Kritis). EduHumaniora: Jurnal Pendidikan Dasar, Vol. 9. No.1 Januari 2017, 2734.

Fien, John. Education for the Environment. Victoria: Deakin University, 1993.

Kahn, Richard. (2010). Critical pedagogy, ecoliteracy, \& planetary crisis: The ecopedagogy movement. New York: Peter Lang.

Tara, Ardyanto. 2013. Penerapan Kurikulum Pendidikan Lingkungan Hidup. http://biasadiangkringan.blogspot.c $\mathrm{om} /$ search?q=penerapan+kurikulu m (Online). Diakses Pada 12 September 2020 Pukul 21.13 WIB

Arif, Saiful. (2007). Ekologi Manusia dan Kesadaran Individu dalam Pengelolaan Lingkungan. www.averroes.or.id diunduh pada tanggal 13 Agustu 2019 pukul 09.30. https://www.averroes.or.id/ekologimanusia-dan-kesadaran-individudalam-pengelolaanlingkungan.html.

Herlambang, Yusuf Tri. (2018). Pedagogik (Telaah Kritis Ilmu Pendidikan dalam Multiperspektif). Tasikmalaya: Ksatria Siliwangi.

Muhaimin. (2014). Membangun Kecerdasan Ekologis. Bandung: Alfabeta. 